HJIMB Vol 1, No. 2 2019, pp: 08- 11

https://doi.org/10.30606/hiimb

\title{
HIRARKI
}

Jurnal Ilmiah Manajemen dan Bisnis http://iournal.upp.ac.id/index.php/Hirarki

\section{PENGARUH PROMOSI DAN MUTASI TERHADAP PRESTASI KERJA PEGAWAI DINAS PERHUBUNGAN ROKAN HULU}

\author{
Efrieyul Hendra \\ Managemen Faculty, University of Pasir Pengaraian
}

\section{Info Artikel}

Sejarah Artikel:

Diterima 30 Agustus

2019

Disetujui 30 September 2019

Dipublikasikan

30 Oktober 2019

\section{Keywords:}

Promosi; Mutasi; Prestasi Kerja.

\begin{abstract}
Abstrak
Penelitian ini bertujuan untuk mengetahui seberapa besar pengaruh promosi dan mutasi terhadap prestasi kerja pegawai di Dinas Perhubungan Rokan Hulu. Responden kunci (key informan) yang digunakan dalam penelitian ini adalah beberapa orang pegawai Dinas Perhubungan Rokan Hulu dan teknik pengambilan data yang digunakan adalah observasi, dokumentasi dan wawancara. Hasil penelitian ini menunjukkan bahwa promosi dan mutasi memiliki pengaruh yang nyata terhadap peningkatan kinerja pegawai, pegawai Dinas Perhubungan Rokan Hulu memiliki ketaatan pada aturan, semua aturan yang ditetapkan oleh pimpinan dalam menciptakan kinerja yang baik agar dapat dilaksanakan untuk mencapai tujuan organisasi. Saran adalah pimpinan hendaknya tetap memantau kinerja pegawai, sehingga para pegawai merasa terperhatikan dengan baik. Hal ini akan meningkatkan kinerja pegawai secara bertahap dan memperbaiki komunikasi antara atasan dan bawahan..
\end{abstract}

THE INFLUENCE OF PROMOTION AND MUTATION ON THE WORK ACHIEVEMENT OF EMPLOYEE'S

\begin{abstract}
This study aims to determine how much influence promotion and mutation has on employee work performance at the Rokan Hulu transportation service. The key respondents (key informant) used in this study were several employees of the Rokan Hulu transportation office and data collection techniques used were observation, documentation and interviews. The results of this study indicate that promotion and transfer have a significant influence on improving employee performance, employees of the Rokan Hulu transportation office have adherence to rules, all rules applied by the leadership in creating good performance can be implemented to achieve organizational goals. Advice is that leaders should continue to monitor employee performance, so that employees feel well cared for this will improve employee performance gradually and improve communication between superiors and subordinates.
\end{abstract}

\footnotetext{
Alamat korespondensi : 


\section{PENDAHULUAN}

Sumber daya manusia atau pegawai merupakan aset utama dari setiap organisasi/perusahaan, karena pegawai sangat menetukan berhasil tidaknya suatu organisasi dalam mencapai tujuan organisasi secara efektif dan efisien, oleh karena itu perusahaan/organisasi selalu berupaya untuk memperoleh pegawai yang terbaik yang malaksanakan pekerjaannya secara baik. Untuk memperoleh pegawai/karyawan yang diharapkan tersebut, dinas perhubungan melakukan berbagai cara, salah satunya adalah melalui pengembangan kualitas sumber daya manusia yang didasarkan pada perhitungan kebutuhan sesuai analisis jabatan dan analisis kebutuhan pegawai tersebut, agar memperoleh pegawai yang benar-benar qualified sesuai dengan kebutuhan organisasi salah satunya adalah dengan cara meningkatkan prestasi kerja dari pegawai/karyawan tersebut. Dalam melaksanakan tugasnya tersebut tentu harus memiliki sumber daya manusia yang berkualitas baik. Dalam meningkatkan prestasi kerja pegawai dapat dilakukan dengan berbagai cara misalnya promosi dan mutasi.

Dengan penilaian prestasi kerja maka pemerintah khususnya Dinas Perhubungan Rokan Hulu dapat mengetahui seberapa mampu pegawai mengerjakan tugas dan tanggung jawab yang diberikan kepadanya. Dengan demikian Dinas dapat menentukan balas jasa yang layak baginya. Dalam penilain prestasi kerja sering muncul berbagai permasalahan salah-satunya adalah tidak semua penilaian sesuai dari semua situasi dan kondisi nyata.

Promosi jabatan dan mutasi Dinas Perhubungan Rokan Hulu merupakan sarana yang dapat mendorong pagawai agar lebih baik atau lebih bersemangat dalam melakukan suatu pekerjaan dalam lingkungan organisasi. Dengan melihat fakta tersebut maka penilaian kerja yang mengarah pada promosi jabatan dan mutasi harus dilakukan dengan efektif agar dapat diterima semua pihak tanpa ada merasa yang dirugikan.

Salah satu tindak lanjut yang dilakukan Dinas Perhubungan Rokan Hulu dari hasil penilaian prestasi pegawai adalah mutasi, karena akan diketahui kecakapan seorang karyawan dalam menyelesaikan uraian pekerjaan (job promotion) yang dibabankan kepadanya. Mutasi termasuk fungsi pengembangan pegawai yaitu meningkatkan efisiensi dan efektifitas kerja.

Sehubung dengan itu agar seorang makin produktif dan kariernya berkembang, memerlukan perlakuan dari organisasi tempatnya bekerja yang meliputi mutasi yaitu pemindahan jabatan yang dilakukan pada tingkat yang sederajat atau setingkat.

Dinas Perhubungan merupakan institusi yang berada diwilayah Kabupaten Rokan Hulu yang mempunyai tugas pokok memberikan pelayanan kepada masyarakat. Namun demikian dalam memberikan pelayanan yang akuntabel, maka diperlukan peranan sumber daya

pegawai yang kompeten, dalam arti pegawai mampu mangaktualisasikan tujuan dari organisasi pemerintahan Kabupaten Rokan Hulu, kerena pegawai selain mampu, cakap dan terampil juga tidak kalah pentingnya memiliki kemauan dan kesungguhan mereka untuk bekerja secara profesional, kemampuan dan kecakapan kurang berarti jika tidak diikuti moral kerja dan kedisiplinan karyawan dalam mewujudkan tujuan dan visi misi organisasi tersebut.

Rivai (2009:548) mengatakan prestasi kerja merupakan suatu fungsi dari motivasi dan kemampuan untuk menyelesaikan tugas atau pekerjaan seseorang yang memiliki derajat kesediaan dan tingkat kemampuan tertentu. 
Amstrong dan Baron dalam Wibowo (2007:2) mengatakan prestasi kerja adalah hasil pekerjaan yang mempunyai hubungan kuat dengan tujuan strategis organisasi, kepuasaan konsumen dan memberikan kontribusi ekonomi.

\section{METODE}

Dalam penelitian ini peneliti mengunakan data kualitatif, yaitu uraianuraian kalimat yang diperoleh berupa informasi penelitian melalui kegiatan wawancara dengan responden penelitian terpilih.

Data primer yang digunakan dalam penelitian ini adalah data mengenai pengaruh promosi dan mutasi terhadap prestasi Pegawai Dinas Perhubungan. Data sekunder dalm penelitian ini meliputi: jumlah karyawan, sejarah berdiri nya, profil dan stuktur organisasi.

Pengambilan data dilakukan dengan cara datang langsung kelokasi dengan tujuan meninjau permasalahan mengenai pengaruh promosi dan mutasi terhadap prestasi kerja pegawai Kantor Dinas Perhubungan Kabupaten Rokan Hulu.

\section{HASIL DAN PEMBAHASAN}

Berdasarkan informasi yang diperoleh dari 3 (tiga) orang pegawai dinas perhubungan Rokan Hulu yang dimutasi bahwa memiliki dampak baik terhadap prestasi kerja pegawai dinas perhubungan rokan hulu, hal ini dapat dilihat dari: Kesetiaan, Kejujuran, Kedisiplinan, Kreatifitas, Kerjasama, Kepemimpinan, Kepribadian, Prakarsa, Kecakapan, Tanggung Jawab.

Informan A Saya dipromosi dari staff menjadi Sekretaris di Dinas Perhubungan Rokan Hulu dari 2017 sampai sekarang, keputusan pemerintah untuk mempromosikan saya dilakukan dengan melihat beberapa syarat yang ada pada diri saya diantaranya, Pengalaman saya sebelum di Dinas Perhubungan Rokan Hulu, saya sudah sering ditempatkan di berbagai dinas yang ada di pemerintah Rokan Hulu. Setiap pekerjaan yang dibebankan kepada saya baik itu pekerjaan yang kecil atau pun yang besar selalu saya prioritaskan dibandingkan diri saya, dan saya juga bertanggung jawab atas apa yang saya kerjakan. Saya selalu berusaha jujur dalam pekerjaan dan tidak ada yang di sembunyikan dalam pekerjaan. Dalam rapat saya selalu memberikan masukan untuk kemajuan dinas dimasa yang akan datang. Dalam hal pergaulan, Saya sangat pandai bergaul, saya selalu membantu rekan kerja saya yang mengalami kesulitan dan mencarinya jln keluar dari masalah tersebut.

\section{Tabel .1 Hasil Olah data}

\begin{tabular}{|c|c|c|}
\hline No & Sebelum Mutasi & Sesudah Mutasi \\
\hline 1. & $\begin{array}{l}\text { Tetap setia terhadap } \\
\text { pekerjaan. }\end{array}$ & $\begin{array}{l}\text { Beban kerja } \begin{array}{l}\text { yang } \\
\text { bertambah } \\
\text { dimutasi. }\end{array} \\
\text { selama }\end{array}$ \\
\hline 2. & $\begin{array}{l}\text { Selalu berusaha jujur } \\
\text { dalam pekerjaan }\end{array}$ & $\begin{array}{l}\text { Tidak ada yang } \\
\text { berubah dalam hal } \\
\text { kejujuran. }\end{array}$ \\
\hline 3. & $\begin{array}{l}\text { Kurang disiplin dan } \\
\text { jarang masuk }\end{array}$ & $\begin{array}{l}\text { Ada peningkatan } \\
\text { dalam hal disiplin dan }\end{array}$ \\
\hline 4. & $\begin{array}{l}\text { Kurang kreatif dalam } \\
\text { melakukan pekerjaan. }\end{array}$ & $\begin{array}{l}\text { sekarang menjadi } \\
\text { contoh bagi staff. }\end{array}$ \\
\hline 5. & $\begin{array}{l}\text { Kurang intens dan } \\
\text { jarang bekerjasama }\end{array}$ & $\begin{array}{l}\text { Lebih kreatif } \\
\text { melakukan pekerjaan. }\end{array}$ \\
\hline 6. & $\begin{array}{l}\text { Kepemimpinan } \\
\text { kurang, karena }\end{array}$ & $\begin{array}{lrr}\text { Lebih intens } & \text { dan } \\
\text { sering bekerja } & \text { sama } \\
\text { pimpinan. }\end{array}$ \\
\hline 7. & $\begin{array}{l}\text { staff } \\
\text { Kepribadian biasa saja } \\
\text { dan berusaha menjadi }\end{array}$ & $\begin{array}{l}\text { Berubah menjadi lebih } \\
\text { baik karena sekarang } \\
\text { mempunyai staff }\end{array}$ \\
\hline 8. & lebih baik & 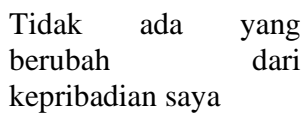 \\
\hline 9. & $\begin{array}{lr}\begin{array}{l}\text { Prakarsa } \\
\text { dalam }\end{array} & \text { ragu-ragu } \\
\text { keputusan } & \end{array}$ & \\
\hline 10. & $\begin{array}{l}\text { Kecakapan biasa saja } \\
\text { dan berusaha menjadi }\end{array}$ & $\begin{array}{l}\text { Lebih berani setelah } \\
\text { mengambil keputusan }\end{array}$ \\
\hline & yang lebih baik & Masih menyesuaikan \\
\hline
\end{tabular}




\begin{tabular}{|l|l|l|}
\hline No & Sebelum Mutasi & Sesudah Mutasi \\
\hline & $\begin{array}{l}\text { Tanggung jawab } \\
\text { kurang tanggung } \\
\text { jawab terhadap tugas } \\
\text { yang di berikan }\end{array}$ & $\begin{array}{l}\text { diri terhadap pekerjaan } \\
\text { yang baru diemban } \\
\text { Meningkat,karena } \\
\text { sekarang memiliki } \\
\text { staff. }\end{array}$ \\
\hline
\end{tabular}

Promosi dilakukan jika prestasi kerja pegawai baik, dalam melakukan promosi harus memenuhi beberapa syarat yang menjadi syarat promosi. Tujuan pemerintah melakukan promosi agar pegawai yang dipromosikan dapat membawa perubahan yang baik bagi instansi khususnya Dinas Perhubungan Rokan Hulu.

Mutasi akan dilakukan jika di suatu instansi jabatan sedang mengalami kekosongan dan harus segera diiisi atau seseorang yang prestasi dinilai kurang

\section{KESIMPULAN}

Berdasarkan data yang telah penulis himpun dan analisa, maka dapat disimpulkan bahwa, Promosi dapat memberikan dampak baik terhadap prestasi kerja pegawai khususnya Dinas Perhubungan Rokan Hulu, selain itu dapat memotivasi pegawai lain dalam menjalankan tugas yang diberikan. Mutasi dapat memberikan dampak baik terhadap prestasi kerja pegawai khususnya Dinas Perhubungan Rokan Hulu. Hal ini dapat dilihat dari kesetiaan, kejujuran, kedisiplinan, kreativitas, kerjasama, kepemimpinan, kepribadian, prakarsa, kecakapan dan tanggung jawab.

\section{SARAN}

Saran yang dapat diajukan kepada pemerintah Rokan Hulu khususnya Dinas Perhubungan Rokan Hulu yaitu, Secara umum promosi dan mutasi di Dinas Perhubungan Rokan Hulu berpengaruh terhadap prestasi kerja pegawai, tetapi baik, Mutasi dilakukan dengan beberapa alasan, diantaranya permintaan sendiri, alih tugas Produktif dan lain-lain. Di Dinas Perhubungan Rokan Hulu terdapat beberapa orang pegawai yang dimutasi karena permintaan sendiri dan alasan lainnya diantaranya jabatan di Dinas Perhubungan Rokan Hulu sedang mengalami kekosongan dan ada juga yang di mutasi yang sudah ditetapkan pemerintah. Dengan alasan tersebut pegawai bekerja dengan penuh tanggung jawab baik didalam dinas perhubungan maupun diluar Dinas Perhubungan.

Dengan adanya promosi dan mutasi ini Dinas Perhubungan mendapat kepercayaan dari pemerintah untuk terwujudnya penyelenggaraan pelayanan transportasi yang handal dalam mendukung visi Rokan Hulu 2021.

dulu latar belakang dari pegawai yang dipromosikan dan dimutasikan. Untuk menerima pegawai yang dimutasikan hendaknya sesuai dengan latar belakang yang dibutuhkan Dinas Perhubungan Rokan Hulu.

\section{DAFTAR PUSTAKA}

A.A. Anwar Prabu Mangkunegara, 2007, Manajemen Sumber Daya Manusia, Cetakan Ke Tujuh PT. Remaja Rosdakarya, Bandung.

Agung Nugroho, 2005. Strategi Jitu Memilih Metode Statistic Penelitian Dengan SPSS, Andi Yogyakarta, Yogyakarta

Abu achmadi H, 2010, metodologi penilitian, bumi aksara, Jakarta 
Bangun Wilson. 2012, Manajemen Jurnal Ekonomi dan Kewirausahaan. Vica

Sumber Daya Manusia, Penerbit Erlangga, Jakarta

Flippo, Edwin B. 1984. Personal Management, Sixth Edition. New York: Mc. Graw-Hill Book Company

Hasibuan Malayu S.P, 2009, Manajemen Sumber DayaManusia, Bumi Aksara, Jakarta.

Iqbal Hasan, M, 2001, Pokok-Pokok Materi Statistik 1 (statistik deskriptip), Bumi Aksara, Jakarta

Jurnal Ilmiah. Arimal Hadi. 2014, Cano Economos Vol 3 No 2 juli. Universitas PasirPengaraian (UPP), Riau.

Jurnal EMBA Agnetha Judas Vol.1 No.4 Desember 2013, Hal. 1219-1228 Universitas Sam Ratulangi Manado
Stevani Dkk Vol. 16 No. 2 Juni 2016: 279 - 286 Universitas Slamet Riyadi Surakarta

Mulyadi dan Rivai (2009) Manajemen Sumber Daya Manusia, Jakarta cetakan kesembilan

Narbuko Kholid, 2010, metodologi penilitian, bumi aksara, jakarta.

Siagian Sondang P, 2009, Manajemen Sumber Daya Manusia, Bumi Aksara, Jakarta.

Sikula, Andrew F. 1981.Personal Administration and human resources Management. New York: A. Wiley Trans Edition, by John Wiley \& Sons Inc

Sugiyono. 2012. Metode Penelitian Kuantitatif Kualitatif dan $R \& D$. Bandung: Alfabeta 